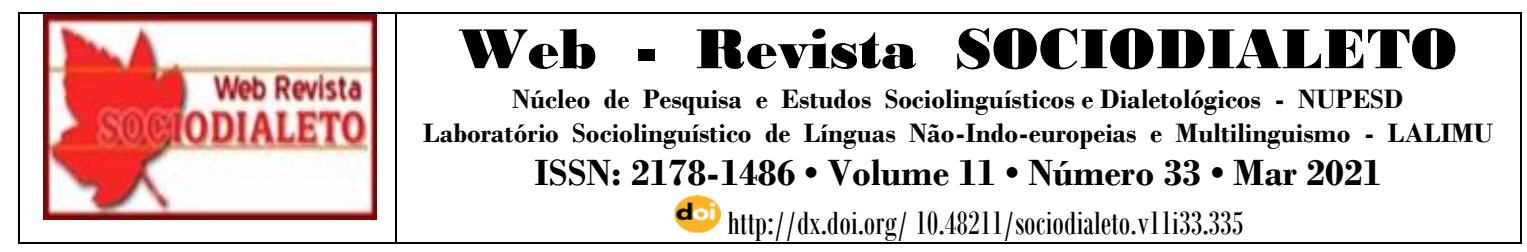

\title{
A LIBRAS DIANTE DA PANDEMIA: A IMPORTÂNCIA DO INTÉRPRETE NO CONTATO LINGUÍSTICO
}

LIBRAS IN THE FACE OF PANDEMIC: THE IMPORTANCE OF THE INTERPRETER IN LINGUISTIC CONTACT

\author{
Bruno Roberto Nantes Araújo (PPGE-UCDB/UFMS) ${ }^{1}$ \\ nantejonantes@gmail.com \\ Rogério Vicente Ferreira (UFMS) ${ }^{2}$ \\ rogerio.v.ferreira@ufms.br
}

\begin{abstract}
RESUMO: Nosso trabalho aborda o fazer do Intérprete/Tradutor de Língua de Sinais (TILS) frente a pandemia causada pela Covid-19. Este profissional sempre tem se deparado com desafios da língua(gem), isso devido ao imenso contato linguístico que essa comunidade de fala possui. Assim, com o aumento de Lives musicais durante a pandemia, o trabalho de interpretação/tradução para as pessoas surdas, para que eles também tivessem acessibilidade cultural foi impulsionado. Com isso, os TILS do Brasil foram solicitados pelos cantores e produtores para que que dessem sentido às letras das músicas apresentadas nestas Lives. É de conhecimento entre estes profissionais que "o intérprete precisa ter uma variedade de estratégias de interpretação flexíveis para responder às exigências únicas em um ambiente multilíngue e multicultural" (SHENEMAN; COLLINS, 2016, p. 171). Assim, esse processo de mediação entre língua e cultura se faz presente no fazer destes profissionais, de forma que é através da língua que nos tornamos membros de uma comunidade de ideias e práticas. A pesquisa tem por embasamento teórico os pressupostos de Quadros (2004, 2011), Gesser (2009), Lacerda (2011), Cavalcanti; Bortoni-Ricardo (2007).
\end{abstract}

PALAVRAS-CHAVE: Libras, Tradução, Interpretação, Políticas linguísticas, Línguas de Contato

\begin{abstract}
Our work deals with the sign language interpreter / translator (TILS) facing the pandemic caused by Covid-19. This professional has always faced language challenges, due to the immense linguistic contact that this speech community has. Thus, with the increase in Musical Lives during the pandemic, the work of interpretation/ translation for deaf people, so that they also had cultural accessibility was boosted. As a result, TILS from Brazil were requested by singers and producers to make sense of the lyrics of the songs presented in these Lives. It is well known among these professionals that "the interpreter needs to have a variety of flexible interpretation strategies to respond to unique requirements in a multilingual and multicultural environment" (SHENEMAN; COLLINS, 2016, p. 171). Thus, this process of mediation between language and culture is present in the making of these professionals, so that it is through language that we become members of a community of ideas and practices. The research is theoretically based on the assumptions of Quadros (2004, 2011), Gesser (2009), Lacerda (2011), Cavalcanti; Bortoni-Ricardo (2007).
\end{abstract}

KEYWORDS: Libras, Translation, Interpretation, Language policies, Contact languages

\footnotetext{
${ }^{1}$ Doutorando em Educação pelo Programa de Pós-Graduação em Educação (PPGE) da Universidade Católica Dom Bosco (UCDB), professor assistente na Universidade Federal de Mato Grosso do Sul (UFMS).

${ }^{2}$ Doutor em Linguística pela Universidade Estadual de Campinas, Professor Associado IV da Universidade Federal de Mato Grosso do Sul, atuando nos cursos de graduação e de pós-graduação Estudos de Linguagens, com pós-doutorado pela USP (2013) e pela UNICAMP (2016).
} 


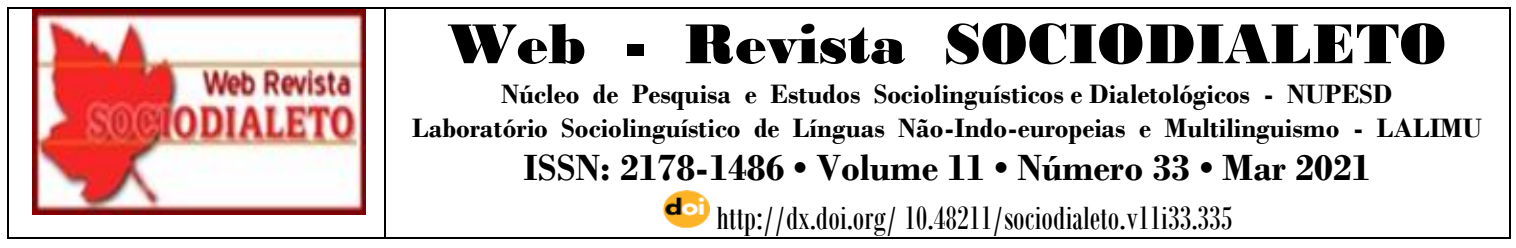

\section{Introdução}

A Libras, segundo Rodrigues e Silva (2017), tem sua existência no Brasil a partir de 1857, quando o Instituto nacional para Educação de pessoas Surdas foi fundado. Os autores colocam que "somente a partir da institucionalização da educação de surdos, surgiram os primeiros registros lexicográficos da língua e o interesse de profissionais em garantir a sua sobrevivência e difusão.” (p. 691). Assim, o reconhecimento da Libras como segunda língua oficial do Brasil, como também o reconhecimento de ser a primeira língua dos surdos brasileiros, veio através da Lei de $\mathrm{N}^{\circ}$ 10.436/02.

No Brasil ainda se tem a ideia errônea de que estamos em um país monolíngue, assunto este discutido em vários artigos (CALLOU, LEITE, 2002; CAVALCANTI; BORTONI-RICARDO, 2007; MÜLLER DE OLIVEIRA, 2010, entre outros).

Müller de Oliveira (2010) ao discutir sobre o Preconceito Linguístico e o Monolinguismo, começa fazendo a indagação:

\footnotetext{
A concepção que se tem do país é a de que aqui se fala uma única língua, a língua portuguesa. Ser brasileiro e falar o português (do Brasil) são, nessa concepção, sinônimos. Trata-se de preconceito, de desconhecimento da realidade ou antes de um projeto político - intencional, portanto, - de construir um país monolíngüe? (MÜLLER DE OLIVEIRA, 2010, s/p)
}

A resposta a essa questão é a seguinte: há uma discriminação em relação a todas as outras línguas vigentes no país, que além das mais de 170 línguas indígenas, as línguas de imigrantes (estas ignoradas dentro de qualquer ação de uma política linguística), e a língua brasileira de sinais. Essa discriminação leva ao preconceito linguístico e à falta de uma política linguística que dê atenção a essa diversidade de línguas. A Libras já teve seu reconhecimento, como supracitado. Contudo, ainda faltam muitas ações voltadas para as pessoas surdas, apesar do grande ganho nos últimos anos. Rodrigues e Silva (2017, p. 691) colocam que a Libras se encontra "como uma ilha linguística num mar de português. Desse modo, o contato com o português é inevitável". 


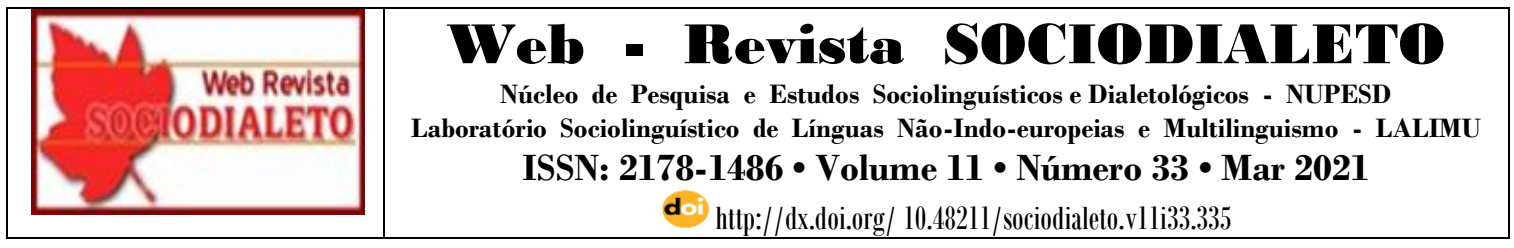

\section{A Libras dentro do contexto de um "novo normal"}

No ano de 2020, momento este que muitas das ações voltadas para a comunidade surda foram suspensas, tendo em conta a recomendação da Organização Mundial da Saúde (OMS) de isolamento social, na tentativa de desacelerar a disseminação da COVID-19, novas formas para amenizar a ansiedade e diminuir a tensão e o pavor mundial foram sendo desenvolvidas e/ou adaptadas para garantir uma quarentena mais eficaz. As tecnologias durante este período se tornaram de fato instrumentos importantes que serviram para ampliar o acesso às informações, como também estabelecer conexões virtuais e contribuir para as interações, que vieram somar-se ao entretenimento cultural e artístico a toda sociedade. Pensando na inserção e o acesso dos surdos nestas áreas culturais como também acesso à informação linguística, além das educacionais, Macedo (2016) coloca o seguinte:

Portanto, a presença do intérprete é importante para que aconteça a inclusão das pessoas surdas nos diferentes espaços, mas, nos espaços educacionais, não há necessidade apenas da transmissão de ideias, mas também da interação entre os pares, produção de sentidos e construção de conceitos. (MACEDO, 2016, p. 31)

Assim, sem uma política linguística adequada para a comunidade surda no momento de pandemia, o tradutor e intérprete de língua de sinais tiveram um papel importantíssimo nas ações do preconizado "novo normal" mediante sua prática e seu (re)fazer nas atuações em aulas remotas, nas Lives musicais que se utilizaram das plataformas digitais (youtube, facebook, instagram, entre outros), como também na mídia televisiva, por meio dos telejornais, além de noticiários na mídia digital. Pensando positivamente em meio a todo este caos, o isolamento e o distanciamento social contribuíram para dar grande visibilidade a estes profissionais.

Os TILs remontam um recurso humano imprescindível e, neste momento da pandemia, foram acionados nos ambientes virtuais previamente citados promovendo assim a acessibilidade dos surdos, conforme a Lei de $n^{\circ}$ 10.098/00, Lei de Acessibilidade, que é o caso da comunicação e do acesso às informações através da língua de sinais. E também respaldada pela Lei $n^{\circ} 13.146$ de julho de 2015, a Lei Brasileira de Inclusão da 


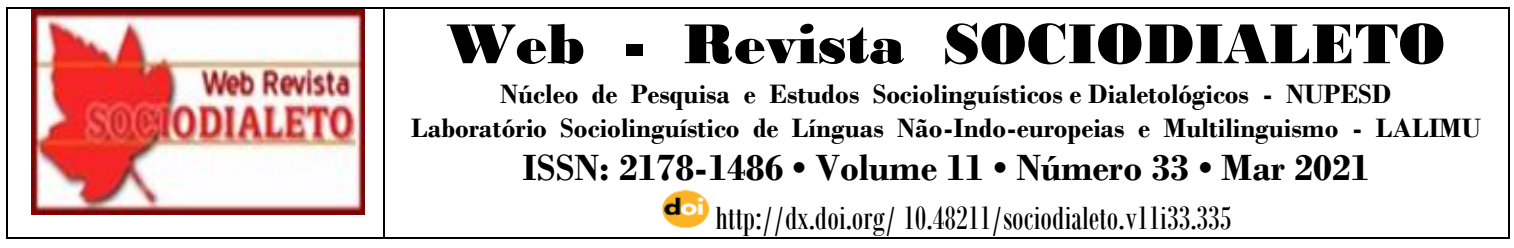

Pessoa com Deficiência (Estatuto da Pessoa com Deficiência) que dispõe em seu Art. $1^{\circ}$ "assegurar e a promover, em condições de igualdade, o exercício dos direitos e das liberdades fundamentais por pessoa com deficiência, visando à sua inclusão social e cidadania.” (BRASIL, 2015).

Foi a partir de Lives de cantores sertanejos por meio da plataforma de vídeos YouTube - que os TILs foram se destacando a nível nacional e, consequentemente, despertando diversos comentários e elogios dos surdos e de colegas de profissão. A comunidade surda popularizou-se nas redes sociais e a Língua Brasileira de Sinais (Libras) ganhou maior visibilidade pela sociedade.

Logo no início da Pandemia da Covid-19 no país, a Federação Brasileira das Associações dos Profissionais Tradutores e Intérpretes e Guia-Intérpretes de Língua de Sinais - FEBRAPILS ${ }^{3}$ se preocupou em atender as novas medidas de recomendações da OMS, Ministério da Saúde, da Anvisa e da Legislação em Segurança do Trabalho divulgando uma carta aberta no dia 18 de março, do presente ano, direcionada aos Tradutores, Intérpretes, e Guia-intérpretes de todo o país a respeito da Covid-19.

Seguir as recomendações foi de extrema importância para a preservação da saúde do profissional nos seus espaços de trabalhos, principalmente nestas novas formas de trabalho ofertadas pelas mídias neste período de pandemia. Somando-se a estas precauções, também houve medidas e decretos estaduais e municipais para uso obrigatório de máscaras para evitar o contágio pelas vias aéreas. Algumas organizações, pensando nos surdos em geral, naqueles que fazem a leitura labial e que se utilizam de sinais não manuais, também articulando com o apoio da oralidade, criaram uma máscara especial, de forma que a parte da boca fique aparente por meio de um plástico transparente e, assim, com a boca visível, a comunicação se torna possível.

\footnotetext{
${ }^{3}$ É uma entidade profissional autônoma, sem fins lucrativos ou econômicos, fundada em 22 de setembro de 2008 e duração indeterminada, com personalidade jurídica de direito privado, qualificável como de interesse público e pertencente ao território brasileiro. Tem a função de orientar, apoiar e consolidar as Associações de Tradutores, Intérpretes e Guia-intérpretes de Língua de Sinais (APILS), buscando realizar um trabalho de parceria em defesa dos interesses da categoria de tradutores, intérpretes e guia-intérpretes de língua de sinais (TILS). Disponível em: <http://febrapils.org.br> Acesso: 23 set. 2020.
} 


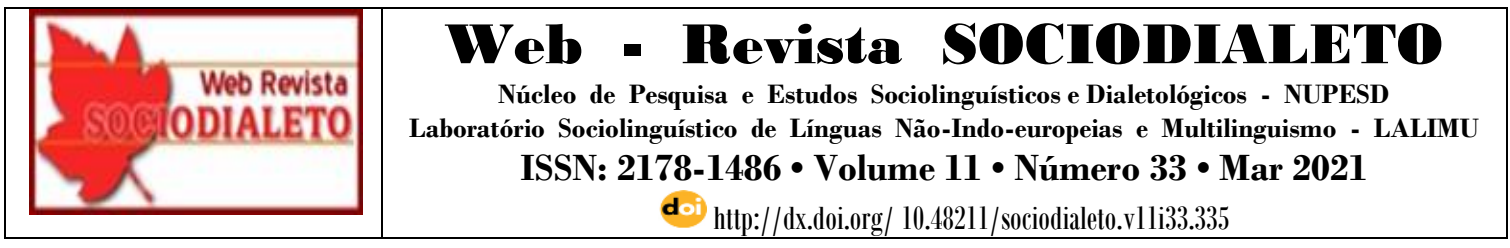

Adequações foram assumidas pelas secretarias de educação do Estado de Mato Grosso do Sul e do Município de Campo Grande, em parceria com alguns canais de televisão da cidade, e se engajaram em produzir vídeo-aulas com os professores, e, novamente, a atuação dos TILS foram de grande importância para as traduções das aulas.

\subsection{O fazer na língua de sinais: o papel do tradutor e intérprete (TILS) frente ao contato linguístico}

O intéprete/tradutor, segundo Sheneman e Collins (2016, p. 171 apud GRANADO, 2109, p. 217), “[...] precisa ter uma variedade de estratégias de interpretação flexíveis para responder às exigências únicas em um ambiente multilíngue e multicultural". Outro ponto importante é a importância dos TILS em terem um bom domínio de um certo tema, pois é necessário conhecer e compreender o assunto para fazer um trabalho de qualidade, mesmo este profissional não sendo da área que irá interpretar. Como coloca Lacerda (2011, p. 17), "tanto a tradução quanto a interpretação precisam ser realizadas por profissionais capazes de compreender e expressar ideias relacionadas, às diferentes áreas de conhecimento humano.”

O TILS já foi visto como aquele que tinha certo conhecimento da Libras e que se dispunha a acompanhar as pessoas surdas nas mais diversas atividades sociais, cujo aprendizado da Libras ocorria em contato linguístico com familiares de surdos, ou em espaços religiosos. Estes trabalhos, ainda informais, ocorriam, em sua grande maioria, em regime de voluntariado e de caráter assistencialista.

Na década de 80, a Língua de Sinais foi sendo respeitada e, consequentemente, os TILS em ambientes sociais começaram a ser mais perceptíveis. Neste interim, foram surgindo as primeiras associações de surdos através de seus familiares, como também as organizações como: as Federações de Surdos (FENEIS) e os Tradutores e intérpretes de Língua de Sinais (FEBRAPILS). Segundo Nantes, foi

A partir de 1988, a FENEIS inicia uma descrição das atividades desse profissional como atuação em órgãos públicos, empresas, bancos, 


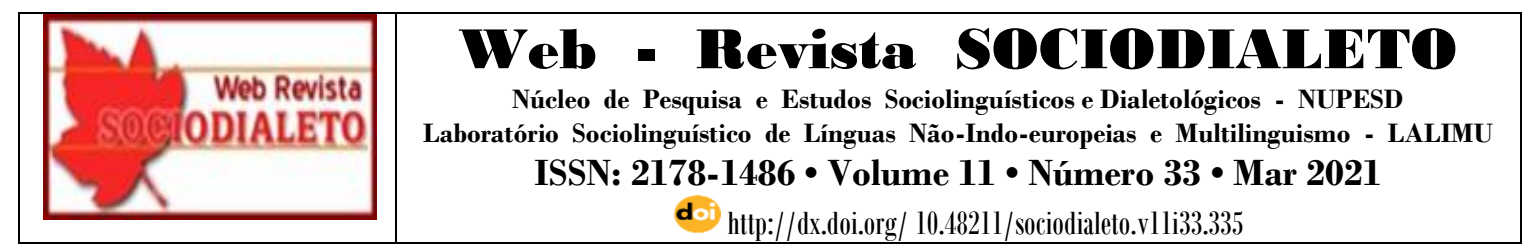

eventos e outros. Fato que concorreu para o abandono gradativo da função de voluntariado para exercício de um trabalho remunerado (2012, p.52).

$\mathrm{Na}$ década de 90, por reivindicações dos próprios surdos e movidos por uma perspectiva educacional inclusiva, a demanda dos TILS nas escolas foi fortalecida (Albres, 2015), porém foi somente a partir do Decreto 5.626, de 2005, que se regulamentou a lei voltada para Libras, assim estipulando a necessidade de uma formação específica para se poder exercer a profissão. Isso pode ser conferido no capítulo $\mathrm{V}$ do Decreto 5.626, que trada da formação do tradutor e intérprete de Libras - Língua Portuguesa, encontra-se o Art. 17, que diz: "A formação do tradutor e intérprete de Libras - Língua Portuguesa deve efetivar-se por meio de curso superior de Tradução e Interpretação, com habilitação em Libras - Língua Portuguesa."

Goes e Santarosa colocam que

Não existindo este profissional para o ensino de Libras, com formação em nível superior, a UFSC pleiteou e obteve junto ao MEC a autorização para a criação do curso, na modalidade a distância, em observância ao decreto $\mathrm{n}^{\circ} 5.626 / 2005$. O curso de Letras/Libras busca garantir a inclusão social de surdos na sociedade por meio de formação acadêmica, abrindo espaço para a sua inserção no mercado de trabalho (2017, p. 211).

Somando-se a formação de um profissional para o trabalho com Libras, a UFSC também desenvolve o Exame do Prolibras - Exame Nacional de Proficiência em tradução e interpretação na Língua Brasileira de Sinais. Esta universidade criou também os cursos de Licenciatura e bacharelado em Letras Libras. (QUADROS e STUMPF, 2015).

Com a legislação em vigor, as universidades, cumprindo o seu papel de formação e capacitação destes profissionais, criou um ambiente favorável de valorização e formalização dos direitos e deveres dos TILS, bem como, novos espaços de laboração e fomento de novos estudos e pesquisas. Um dos grandes avanços foi a regulamentação do exercício da profissão Tradutor e Intérprete da Língua Brasileira de Sinais - LIBRAS, pela da Lei $\mathrm{n}^{\circ}$ 12.319/10. Tendo em seu Art.6º as atribuições e competências: 


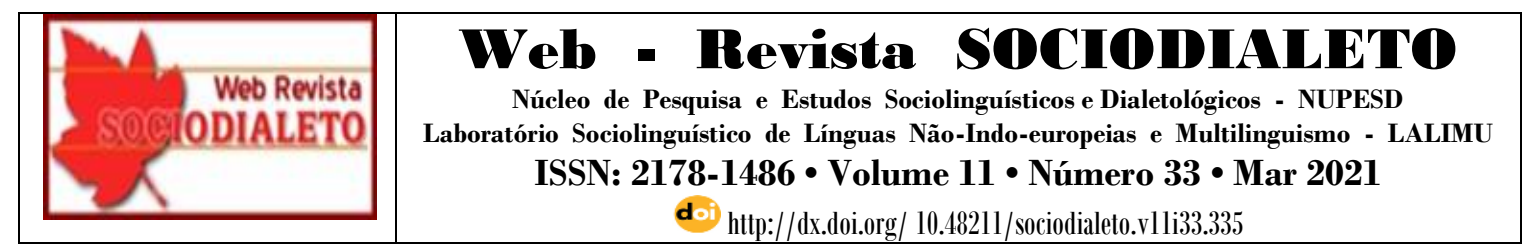

I - efetuar comunicação entre surdos e ouvintes, surdos e surdos, surdos e surdos-cegos, surdos-cegos e ouvintes, por meio da Libras para a língua oral e vice-versa; II - interpretar, em Língua Brasileira de Sinais - Língua Portuguesa, as atividades didático-pedagógicas e culturais desenvolvidas nas instituições de ensino nos níveis fundamental, médio e superior, de forma a viabilizar o acesso aos conteúdos curriculares; III - atuar nos processos seletivos para cursos na instituição de ensino e nos concursos públicos; IV - atuar no apoio à acessibilidade aos serviços e às atividades-fim das instituições de ensino e repartições públicas; e V - prestar seus serviços em depoimentos em juízo, em órgãos administrativos ou policiais. (BRASIL, 2010)

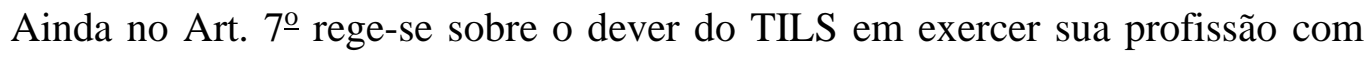
rigor técnico, zelando pelos valores éticos a ela inerentes, pelo respeito à pessoa humana e à cultura do surdo, em BRASIL (2010) tem-se:

I - pela honestidade e discrição, protegendo o direito de sigilo da informação recebida; II - pela atuação livre de preconceito de origem, raça, credo religioso, idade, sexo ou orientação sexual ou gênero; III pela imparcialidade e fidelidade aos conteúdos que lhe couber traduzir; IV - pelas postura e conduta adequadas aos ambientes que frequentar por causa do exercício profissional; $\mathrm{V}$ - pela solidariedade e consciência de que o direito de expressão é um direito social, independentemente da condição social e econômica daqueles que dele necessitem; VI - pelo conhecimento das especificidades da comunidade surda.

Aqui destaca-se o item V, sobre a importância deste profissional compreender e ter a consciência dos aspectos que envolvem no exercício de seu trabalho em sua totalidade, tanto no caráter solidário e social perante a comunidade surda, quanto na atualidade, atuando profissionalmente de forma a promover acessibilidade, empatia, de respeito ao outro. Quadros (2007) descreve sobre o papel do intérprete e afirma que este deve seguir alguns preceitos éticos, como a confiabilidade, imparcialidade, discrição, distância profissional e a fidelidade. 


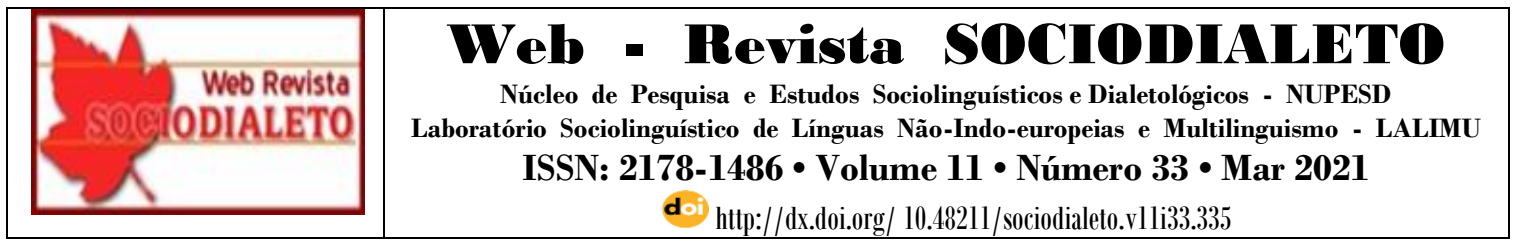

\section{A experiência como TILS: a importância do intérprete no contato linguístico}

Tendo em vista que "[...] os intérpretes são treinados em sua língua nativa e na língua de sinais nacional (Wit, 2010), eles contam com seu próprio conhecimento do idioma e da cultura das comunidades com as quais trabalham (Reagan, 2010). [...] intérpretes geralmente são treinados em duas línguas e culturas" (SHENEMAN; COLLINS, 2016, p. 170).

Adquirimos estes conhecimentos colocado por Sheneman e Collins quando trabalhei no Centro Estadual de Atendimento ao Deficiente da Audiocomunicação (CEADA), construí amizades, agreguei. Neste local tivemos o privilégio de estar a frente do coral de Libras do CEADA, formado pelos alunos surdos de todas as idades. Apresentávamos em diversos tipos de eventos, aberturas de cerimônias solenes, festivais, congressos, entre outros.

Uma atividade que fazíamos era a tradução de músicas, isso ocorria junto de professores surdos (aquele momento de tradução era importante do ponto de vista cultural) de forma que as músicas pudessem alcançar o sentido e a compreensão dos surdos e, consequentemente, também a dos ouvintes. Como coloca Luchi (2013, p. 41 apud GRANADO, 2109, p. 221) "nas línguas de sinais há duas formas de produção de significado, uma pelas Estruturas Altamente Icônicas (EAI) e a outra pelo léxico padrão e apontamentos manuais", sendo desta forma que trabalhei com músicas como o hino nacional brasileiro, o hino do estado (Mato Grosso do Sul) e do município (Campo Grande). Além das canções regionais, tais como, "Mercedita”, “A Chalana”, "É preciso saber viver", entre outras canções nacionais. Estas experiências, com interpretação de músicas para a Libras, proporcionaram-nos uma ampla bagagem de conhecimento e até hoje colegas TILS solicitam apoio e sugestões em suas traduções.

Atualmente, realizamos pequenas contribuições para os amigos surdos na sociedade, sempre dependendo da necessidade e da minha possibilidade, bem como para ex-alunos surdos e para seus familiares. Sempre nos colocamos a disposição para colaborar com colegas TILS no que tange a emitir opiniões sobre interpretações e vocabulários para Libras. Por exemplo, neste momento de quarentena fomos solicitados 


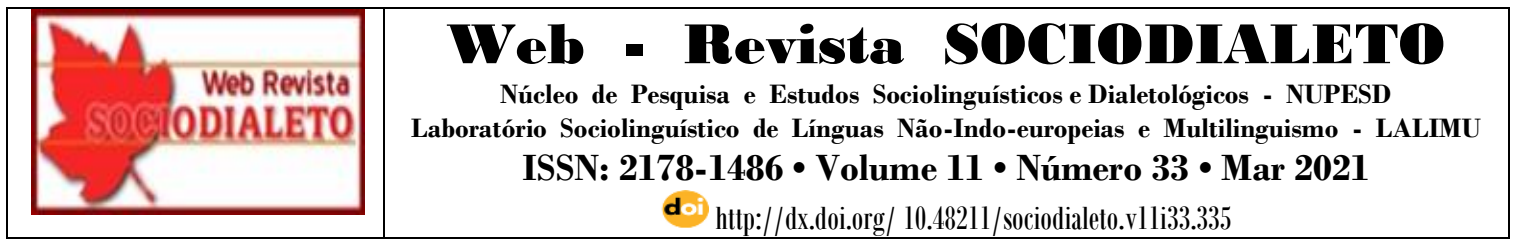

por duas colegas TILS, que iriam fazer o trabalho de tradução e interpretação em uma Live musical para uma dupla sertaneja bastante conhecida nacionalmente. Aceitemos o desafio, pois era uma oportunidade de relembrar, treinar e praticar a Libras nas traduções das letras das músicas, o que proporcionaria retomar as técnicas de tradução e de interpretação, pois fazendo recordar que neste tipo trabalho existem muitas figuras de linguagem e metáforas.

Após termos combinado um horário em que todos pudéssemos nos reunir para discutirmos sobre as letras das músicas, a reunião ocorreu por vídeo-chamadas como recomenta a OMS. Vale ressaltar que as colegas TILS são profissionais formadas e com bastante fluência e experiência em língua de sinais, são efetivas em instituições de Ensino Superior, ou seja, são capacitadas para esse trabalho e atuação, mesmo sendo outro tipo de modalidade de interpretação, no caso a musical.

Segundo Sheneman e Collins (2016, p. 171), “[...] o intérprete precisa ter uma variedade de estratégias de interpretação flexíveis para responder às demandas únicas em um ambiente multilíngue e multicultural." Tendo isso em mente como parte de nosso trabalho, o processo de tradução e de interpretação deu-se da seguinte forma: selecionamos as músicas e começamos as leituras das letras das músicas, entendê-las no seu sentido e significado real em contextos variados, procurando sinais que viessem se adequar naquele contexto. Era o momento de procurarmos os sinais nos glossários de língua de sinais, como também observarmos outros TILS atuando nas Lives e vídeos na internet, para encontrarmos o melhor sinal para aquela música.

Foi bem interessante a percepção e o olhar de cada TILS no processo dessa construção e transposição para a Libras. O que sempre atentávamos era como os surdos entenderiam certa letra de música, nossa preocupação era na compreensão do surdo mediante a nossa tradução e, consequentemente, a interpretação.

Lacerda (2011) explica que "este trabalho de interpretação não pode ser visto apenas como um trabalho linguístico, é necessário considerar a esfera cultural e social na qual o discurso está sendo enunciado.” É importante o conhecimento da gramática da língua, o uso dos diferentes usos da linguagem na atividade humana. Além disso, Cox e Assis-Peterson (2007, p. 32) colocam que, a partir de um dos conceitos de cultura 


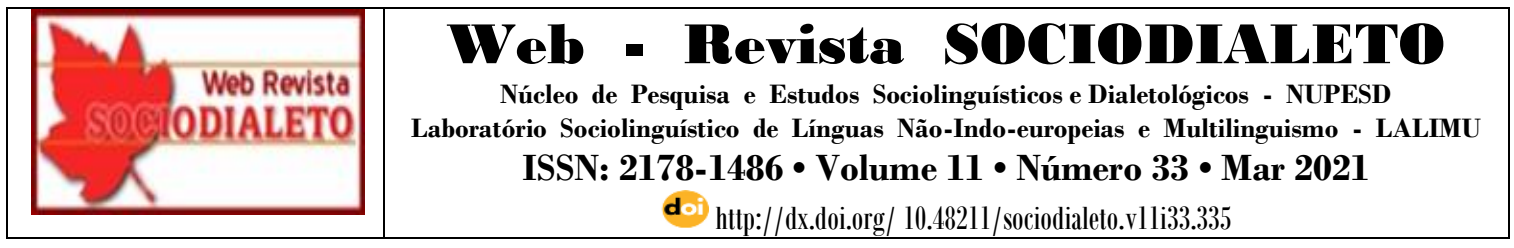

abordados por Duranti em seu livro Linguistic Anthropology, "O sujeito ator humano existe culturalmente [...]".

Nosso primeiro passo do processo, estudar letras das canções, compreender os sentidos e os significados, e procurar os sinais que mais se aproximavam naquela informação lexical e frasal do contexto. Sendo que muitas vezes foi preciso o uso de empréstimos da língua portuguesa para que o se pudesse manter o sentido.

Após os estudos e as seleções dos sinais, dos classificadores ${ }^{4}$, iniciamos o segundo passo, que seria colocar o áudio das músicas para ouvirmos as melodias, assimilarmos os ritmos, e então, inserirmos os sinais dentro da interpretação. Foi algo bastante curioso e cômico o processo de organização dos sinais, as expressões faciais e corporais, principalmente nas canções que só continham duplo sentido e de muita conotação sexual. Precisávamos fazer a interpretação fiel da letra da música, além de ter que trabalhar o movimento corporal de acordo com o seu ritmo. Neste momento havia a influência da vivência musical de cada TILS, o que passou a ser um tanto quanto complexo traduzir e sincronizar os sinais ao ritmo da música, além de acrescentar as expressões faciais e corporais. Após termos feito todo esse processo de construção, somando-se o distanciamento, pois cada um se encontrava em sua residência, nos reunimos via o Google Meet, assim, organizamos os melhores ângulos para treinarmos com o áudio de algumas músicas. Este momento foi bastante interessante, pois podíamos fazer algumas correções nas posturas, nas expressões corporais e faciais das colegas.

Ao chegar o dia da Live, as TILS foram ao local da gravação ao vivo da Live no horário devido, tomando todos os cuidados necessários, segundo o protocolo de biossegurança da produção. A surpresa foi que as produtoras de vídeos e de gravação ainda não estavam preparadas para essa realidade de tradução de Libras. Com isso, foram elas mesmas que sugeriram para a realização das gravações, no que se refere ao posicionamento dos TILS diante da câmera de vídeo, da iluminação, do espaço adequado para a movimentação e da troca das profissionais. Quanto a nossa participação, ela

\footnotetext{
4 Segundo Pizzio et al (2009, p. 13) “O classificador é um tipo de morfema, utilizado através das configurações de mãos que podem ser afixado a um morfema lexical (sinal) para mencionar a classe a que pertence o referente desse sinal, para descrevê-lo quanto à forma e tamanho, ou para descrever amaneira como esse referente se comporta na ação verbal (semântico)."
} 


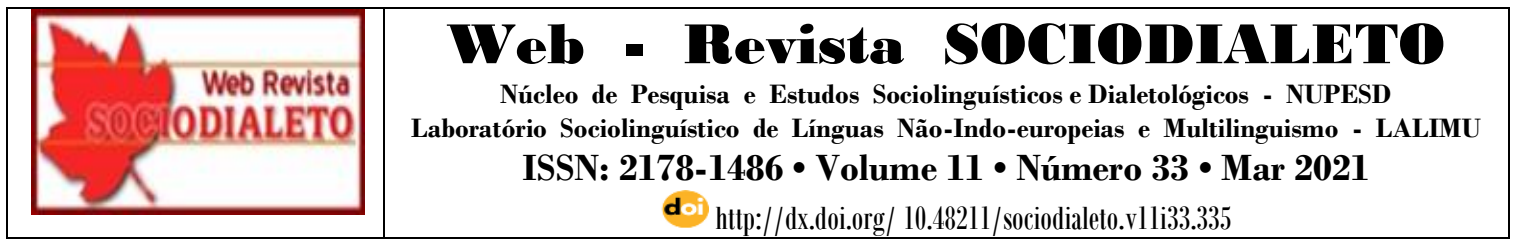

continuou à distância como consultor, assistindo a Live e vendo as interpretações das colegas. Com isso, passava algumas informações para adequações e novas sugestões, tudo foi feito através de mensagens nos intervalos das músicas, dessa forma, pudemos retornar para as TILS em tempo real.

Sem dúvidas esta experiência foi inovadora, inusitada e extremamente gratificante! Toda a formação, capacitação e o preparo que antecedem os estudos de tradução e trocas colaboraram muito para uma boa interpretação. Mesmo acontecendo na modalidade à distância conseguimos preparar novos caminhos de atuação para os TILS. Esse trabalho trouxe para estas minhas colegas uma visibilidade nacional e foram reconhecidas com bastantes elogios, principalmente nos comentários do Chat da Live e nas redes sociais delas, além de proporcionarem o direito de acessibilidade aos cidadãos surdos na cultura.

Apesar da pandemia estar assolando não só o país, mas o mundo, essas alternativas culturais para amenizar as dores, as angústias e os medos foram de grande relevância a todos, o que proporciona momentos de entretenimento para todas as pessoas, sem exclusão, com isso, valoriza, em especial, os surdos e os profissionais tradutores e intérpretes de língua de sinais (TILS). A linguagem e tecnologia para libras ultrapassa as barreiras da língua escrita e oral, que a troca com os colegas TILS nos faz aprender e desenvolver novas habilidades, além de colaborar para a inclusão e acessibilidade dos surdos no Brasil.

\section{Considerações finais}

É possível observar que o intérprete dentro desse contexto de contato linguístico (língua portuguesa e libras) tem um papel crucial quanto ao acesso das pessoas surdas a todo o contexto cultural que estão inseridos.

Apesar dos ganhos de uma política linguística voltada para essa minoria linguística, ainda há muito a ser feito. Com a pandemia, mais uma vez se mostrou a relevância em proporcionar acessibilidade linguística para essa parte da população, como também a importância de profissionais bilíngues em Libras para atender as pessoas surdas 


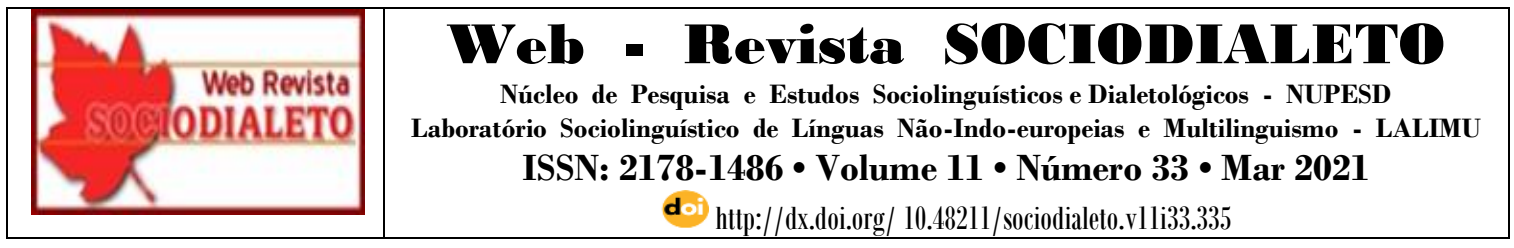

em todo seu contexto cultural. Sem o papel do tradutor/intérprete frente a esta comunidade linguística, mais uma vez estariam deixados de lado, quer seja uma live musical em tempo de pandemia, quer seja em qualquer outro contexto.

Os estudos sobre Libras têm voltado sua atenção para questões relativas à aquisição do português como segunda língua, empréstimos linguísticos, entre outros. Dentro dessa perspectiva, o processo de interpretação necessita sempre buscar uma variedade lexical nova. Para esse artigo, nos limitamos em apenas expor o processo para a realização de um trabalho de interpretação de uma Live dentro do contexto de língua de contato.

\section{Referências bibliográficas}

ALBRES, N. de A. Intérprete Educacional políticas e práticas em sala de aula inclusiva. Editora Harmonia, $1^{a}$ Edição, São Paulo. 2015

BRASIL. Lei $\mathrm{N}^{\circ} 10.098$, de 19 de dezembro de 2000. Estabelece normas gerais e critérios básicos para a promoção da acessibilidade das pessoas portadoras de deficiência ou com mobilidade reduzida, e dá outras providências. Disponível em: <http://www.planalto.gov.br/ccivil_03/leis/L10098.html>. Acesso em 25 ago. 2020.

BRASIL. Lei n. 10.436, de 24 de abril de 2002. Dispõe sobre o reconhecimento da Língua Brasileira de Sinais- Libras. Diário Oficial da República Federativa do Brasil, Brasília, 24 abril de 2002.

BRASIL. Decreto n. 5.626, de 22 de dezembro de 2005. Dispõe sobre a Língua Brasileira de Sinais - Libras, e o art. 18 da Lei no 10.098, de 19 de dezembro de 2000. Diário Oficial da República Federativa do Brasil, Brasília, 23 dez. 2005.

BRASIL. Lei $\mathrm{n}$. 12.319, de $1^{\circ}$ de setembro de 2010. Regulamenta a profissão de Tradutor e Intérprete da Língua Brasileira de Sinais - LIBRAS. Diário Oficial da República Federativa do Brasil, Brasília, 01 de setembro de 2010.

BRASIL. Lei n. $N^{\circ} 13.146$, de 06 de julho de 2015. Institui a lei brasileira de inclusão da pessoa com deficiência (estatuto da pessoa com deficiência). Diário Oficial da República Federativa do Brasil, Brasília, 07 de julho de 2015.

COX, Maria I. Pagliarini; ASSIS-PETERSON, Ana Anônia de. Transculturalidade e Transglossia: para compreender o fonômeno das fricções linguístico-culturais em sociedades contemporâneas sem nostalgia. In CAVALCANTI, Marilda C.; BORTONIRIARDO, Stella Maris. Transculturalidade, Linguagem e Educação. SP: Mercado de Letras, 2007. p.23-44 


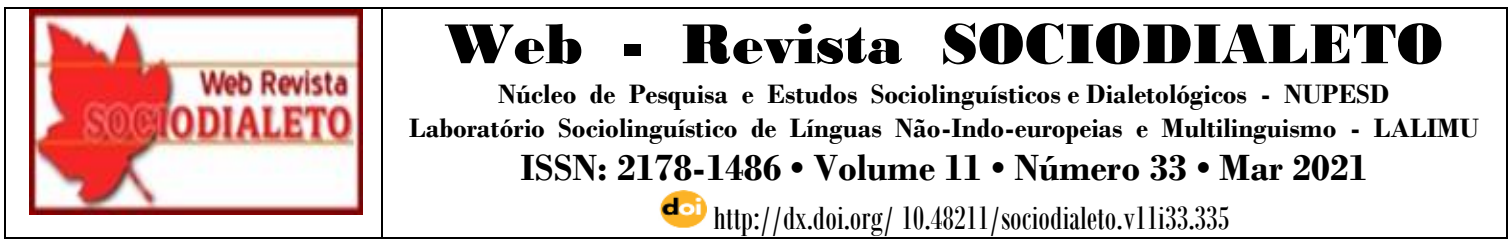

GOES, C. G. G.; SANTAROSA, L. M. C. Experiência com Alunos Surdos no Ambiente Virtual de Aprendizagem do Curso de Letras/Libras/UFSC. Informática na Educação: teoria \& prática, v.20, n. 2, 2017. Disponível em: $<$ https://www.seer.ufrgs.br/InfEducTeoriaPratica/article/view/63701/43629>. Acesso: 07 set. 2020.

GRANADO, Letícia F. G. W. Sinais Internacionais e a formação para intérpretes de Sinais Internacionais. Belas Infiéis, n. 1, v. 8, 2019, p. 211-228.

LACERDA, C. B. de. Intérprete de Libras em atuação na educação infantil e no ensino fundamental. Editora Mediação. $3^{\text {a }}$ Edição, Porto Alegre, RS, 2011.

MACEDO, Lucio L. de. Política Linguística: Instrução em Libras dos Professores Ouvites. Revista Fórum, n. 33, 2016, p. 27-58.

MÜLLER J.; KARNOPP L. Educação escolar bilíngue de surdos In: $37^{\mathbf{a}}$ Reunião Nacional da Anped. 04 a 08 de outubro 2015, Florianópolis, UFSC.

MÜLLER DE OLIVEIRA, Giovan. Brasileiro fala português: Monolinguismo e Preconceito Linguístico. Revista linguasagem, n.1, v.11, 2010.

NANTES, J. M. A constituição do intérprete de língua de sinais no Ensino superior na perspectiva dos surdos: o cuidado de si e do outro. 2012. Dissertação (Mestrado em Educação) - Universidade Federal da Grande Dourados (UFGD).

PIZZIO, Aline L. et al. Língua Brasileira de Sinais III. Florianópolis: CCE, UFSC, $2009 . \quad$ Disponível em: < http://libras.ufsc.br/colecaoLetrasLibras/eixoFormacaoEspecifica/linguaBrasileiraDeSin aisIII/assets/263/TEXTO_BASE_-_DEFINITIVO_-_2010.pdf>. Acesso em 12 out. 2020

QUADROS, R. M. de. Letras Libras, ontem, hoje e amanhã. Editora UFSC, Florianópolis, 2015.

QUADROS, R. M. de. O tradutor e intérprete de língua brasileira de sinais e Língua Portuguesa. Secretaria de Educação Especial; Programa Nacional de Apoio à Educação de Surdos - Brasília: MEC; SEESP, 2004.

QUADROS, R.M.; PIZZIO, A. L.; CAMPELLO, A. R. S.; REZENDE, P. L. F. Língua Brasileira de Sinais III. Universidade Federal de Santa Catarina Licenciatura em LetrasLibras na Modalidade a Distância. Florianópolis, 2009.

RODRIGUES, Angélica; SILVA, Anderson A. de. Reflexões sociolinguísticas sobre a libras (Língua Brasileira de Sinais). Estudos Linguísticos, n. 46, v. 2, 2017.

SHENEMAN, N.; COLLINS, P. F. The Complexities of Interpreting International Conferences: A Case Study. In: ROSENSTOCK, R.; NAPIER, J. (Eds.). International Sign: Linguistic, Usage and Status Issues. Whashington, DC: Gallaudet University Press, 2016. p. 167-191.

SKLIAR, Carlos. Una mirada crítica sobre la educacion bilingue para sordos. Polïtica de las identidades sordas y multiculturalismo. I Congresso Ibero-Americano, Lisboa, Portugal, 1998. 


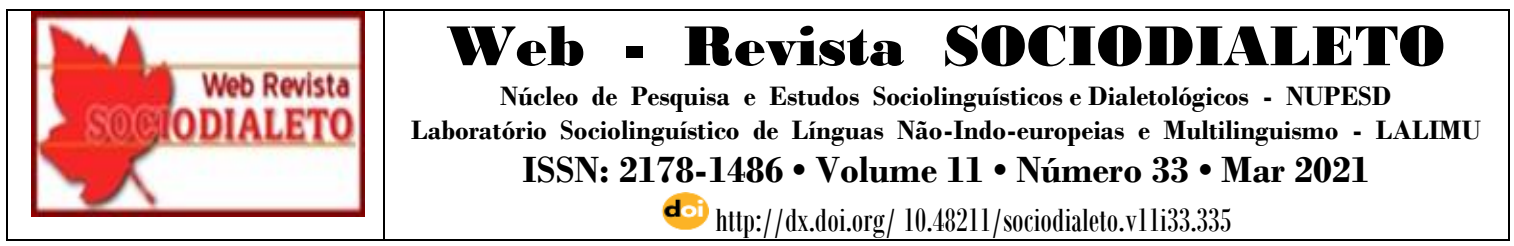

WIT, M. de; SLUIS, I. International Sign: An Exploration into Interpreter Preparation. In: ROSENSTOCK, R.; NAPIER, J. (Eds.). International Sign: Linguistic, Usage and Status Issues. Washington, DC: Gallaudet University Press, 2016. p. 105-135.

Recebido em: 15/10/2020 | Aprovado em: 11/11/2020. 